\title{
NEW RECORDS OF SEED BEETLES (CHRYSOMELIDAE BRUCHINAE) OF THE ASPROMONTE NATIONAL PARK; A STUDY IN THE CALABRIAN APENNINES, ITALY
}

\author{
${ }^{a}$ Department of Infectious Diseases, Istituto Superiore di Sanità. Viale Regina Elena, 299, I-00161 Roma, Italy \\ ${ }^{b}$ GeoLAB - Laboratorio di Geomatica Forestale, Dipartimento di Scienze e Tecnologie Agrarie, Alimentari, Am- \\ bientali e Forestali. Università degli Studi di Firenze. Via San Bonaventura 13, 50145 Firenze, Italy. E-mail: \\ francesco.parisi@unifi.it
}

Corresponding Author: Luciano Toma: luciano.toma@iss.it;

Toma L., Parisi F. - New records of seed beetles (Chrysomelidae Bruchinae) of the Aspromonte National Park; a study in the Calabrian Apennines, Italy.

In this note original data on the Bruchids of the Aspromonte National Park are reported. The specimens examined were surprisingly found within the field activities for a project aimed to deepen the saproxylic coleopteran fauna of the Aspromonte National Park (Calabrian Apennines, Italy), in three different agroforestry systems dominated by chestnut. Out of a total of 134 specimens 129 have been identified as belonging to 3 genera and 14 species, namely: Paleoachantoscelides gilvus (Gyllenhal, 1839), Bruchidius dispar (Gyllenhal, 1833), Bruchidius murinus (Boheman, 1829), Bruchidius olivaceus (Germar, 1824), Bruchidius seminarius (Linnaeus, 1767), Bruchidius tibialis (Boheman, 1829), Bruchidius varius (Olivier, 1795), Bruchidius imbricornis (Panzer, 1795), Bruchidius pygmaeus (Boheman, 1833), Bruchidius trifolii (Motschulsky, 1873), Bruchus brachialis Fahraeus, 1839, Bruchus pisorum (Linnaeus, 1758), Bruchus rufipes Herbst, 1783, Bruchus viciae.

KEY WoRDS: seed beetles, Aspromonte, Calabria, Italy

\section{INTRODUCTION}

Bruchids or seed beetles belong to the Bruchinae subfamily (BOUCHARD et al., 2011) ranging about 1700 species in the world, belonging to 60 genera (SOUTHGATE, 1979; JOHNSON and KINGSOLVER, 1981) and present in Italy with 76 species in 6 genera (ZAMPETTI and RICCI, 2009).

Even if the majority of the species are limited to their natural ranges of distribution a few of them became cosmopolitan because of the passive dispersion by human activities. In fact, also known as seed beetles, Bruchids feed mainly on seeds of Fabaceae (= Leguminosae). Several species became pests of legumes used as a food source for both people and livestock. In general seed trade have caused and still causes, the incoming of these species into Europe from other Countries. Among many species passively imported, some of them become invasive establishing in natural habitats becoming integrated in European ecosystems, especially in the Mediterranean (YUS-RAMOS et al., 2014). For this reason, the local checklists of these coleopterans are often to be updated for the frequent accidental incomings of alien species.

In this note original data on the Bruchids of the Aspromonte National Park (Calabrian Apennines, Italy) are reported as part of the records collected within the URCOFI project (see Acknowledgments), a study aimed to investigate the saproxylic coleopteran fauna of the Aspromonte National Park. The record of seed beetles during this study was surprising, above all because their presence is not actually linked to the chestnut trees characterizing the study area, as well as the method of chosen capture is not selective for these insects. In this context raised the motivation for a contribution to the knowledge on the Bruchids of Calabria region.

The study was carried out on three different agroforestry systems dominated by chestnut: young ( 2 years old; YC) and mature (11 years old; MC) coppice stands located in Santo Stefano in Aspromonte (38.10.48.798N, 15.47.03.510E), and traditional fruit orchard (older than 80 years, TO) located in Cardeto d'Aspromonte $(38.03 .36 .660 \mathrm{~N}, \quad 15.46 .53 .82$. 
000E). The stands occur on similar ecological and environmental conditions, on the borders of the Aspromonte National Park (Fig. I), along an altitudinal gradient ranging $907-1059 \mathrm{~m}$. In the study area, the chestnut fruit orchards, generally of limited extension, are mainly located near small urban areas, in a mosaic of agroforestry systems, which includes chestnut coppice stands and other sparse woodlands, as well as agricultural field crops. The climate is temperate, typical of Mediterranean mountainous environments. Mean annual temperature is around $8^{\circ} \mathrm{C}$, while average minimum and maximum monthly temperatures are $0.5^{\circ} \mathrm{C}$ (the coldest month) and $16^{\circ} \mathrm{C}$ (the warmest month), respectively. Average total annual precipitation is $1200 \mathrm{~mm}$, mainly occurring in the winter season (Meteorological station of Gambarie d'Aspromonte, $1187 \mathrm{~m}$ ). Summer aridity is almost absent, due to the occurrence of frequent orographic precipitation, due to the exposure to the moist air deriving from the Tyrrhenian sea (PARISI et al., 2020).

Each analyzed management type extends on about 12 ha. A total of 60 sampling plots (20 per each management type) were established and located at a regular distance of $50 \mathrm{~m}$ to each other, following a systematic aligned grid (Fig. I, A, I, B and I, C). For each sampling plot, UTM datum WGS84 coordinates (Zone $32 \mathrm{~T}$ ) and altitude $(\mathrm{m})$ were recorded using the Juno SB Global Positioning System (GPS; Trimble, Sunnyvale, California). In YC and MC, each plot extented $530 \mathrm{~m}^{2}$, while, in TO, each plot covered an area of $1963 \mathrm{~m}^{2}$ (PARISI et al., 2020).

The collection of Coleoptera was carried out using window flight traps (WFTs). At the center of each sampling plot, one WFT was positioned at a height of two $\mathrm{m}$ above ground (BOUGET et al., 2008). A total of 60 WFTs were placed, 20 for each of the three management types (PARISI et al., 2020). Traps were checked approximately every 20 days, for a total of four surveys in 2017 (from June to October).

In the study area 134 specimens of Bruchinae were collected by chance. Out of the total 129 specimens have been identified as belonging to 3 genera and 14 species, namely: Paleoachantoscelides gilvus (Gyllenhal, 1839), Bruchidius dispar (Gyllenhal, 1833), Bruchidius murinus
(Boheman, 1829), Bruchidius olivaceus (Germar, 1824), Bruchidius seminarius (Linnaeus, 1767), Bruchidius tibialis (Boheman, 1829), Bruchidius varius (Olivier, 1795), Bruchidius imbricornis (Panzer, 1795), Bruchidius pygmaeus (Boheman, 1833), Bruchidius trifolii (Motschulsky, 1873), Bruchus brachialis Fahraeus, 1839, Bruchus pisorum (Linnaeus, 1758), Bruchus rufipes Herbst, 1783, Bruchus viciae Olivier, 1795. Five specimens have been indentified at genus level only because of the conditions of conservations, namely Bruchus sp. $(\mathrm{n}=2)$, Bruchidius $s p . \quad(\mathrm{n}=3)$. The list of the specimens per species is reported below together with the locus typicus according to ZAMPETTI and RICCI, 2012.

\section{MATERIAL EXAMINED}

Paleoachantoscelides gilvus (Gyllenhal, 1839) - 101 exx., Italy, Calabria, Cardeto d'Aspromonte, 27-29.VI and 3-5.X.2017, L. Carrozza and F. Parisi leg., L. Toma det., in traditional fruit orchard (TO).

Bruchidius dispar (Gyllenhal, 1833) - 2exx., Italy, Calabria, Cardeto d'Aspromonte, 2931.VIII. and 3-5.X.2017, L. Carrozza and F. Parisi leg., L. Toma det., in traditional fruit orchard (TO).

Bruchidius murinus (Boheman, 1829) - exx., Italy, Calabria, Cardeto d'Aspromonte, 27-29.VI and 3-5.X.2017, L. Carrozza and F. Parisi leg., L. Toma det., in traditional fruit orchard (TO). 1 ex., Italy, Calabria, Santo Stefano in Aspromonte 25-27.VII.2017, L. Carrozza and F. Parisi leg., L. Toma det., in young coppice (YC).

Bruchidius olivaceus (Germar, 1824) - 1ex., Italy, Calabria, Cardeto d'Aspromonte, 35.X.2017, L. Carrozza and F. Parisi leg., L. Toma det., in traditional fruit orchard (TO).

Bruchidius seminarius (Linnaeus, 1767) - 2 exx., Italy, Calabria, Cardeto d'Aspromonte, 29-31.VIII and 3-5.x.2017, L. Carrozza and F. Parisi leg., L. Toma det., in traditional fruit orchard (TO). 


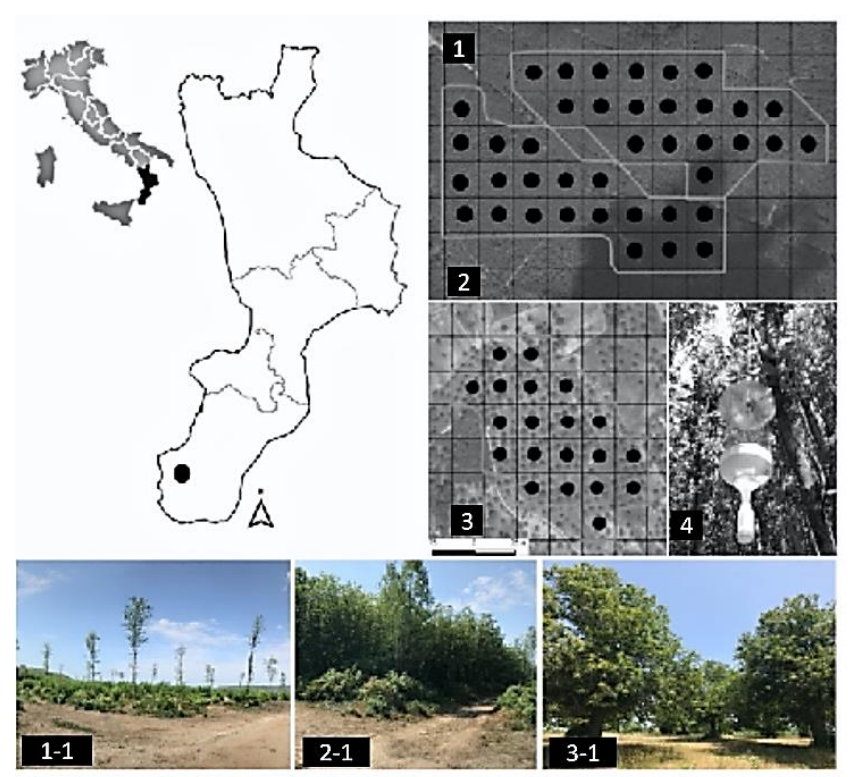

Fig. I - Location of the study area in Southern Apennines (Italy); black dots represent the location of the sampling plots, for each investigated area, where window flight traps were positioned. 1-1) young coppice (YC); 2-1) mature coppice (MC); 3-1) traditional fruit orchard (TO); 4) window flight trap positioned in each sampling plot (from Parisi et al. 2020).

Bruchidius tibialis (Boheman, 1829) - 1ex., Italy, Calabria, Cardeto d'Aspromonte, 35.X.2017, L. Carrozza and F. Parisi leg., L. Toma det., in traditional fruit orchard (TO).

Bruchidius varius (Olivier, 1795) - 3 exx., Italy, Calabria, Cardeto d'Aspromonte, 27-29.VI., 25-27.VII. and 3-5.X.2017, L. Carrozza and F. Parisi leg., L. Toma det., in traditional fruit orchard (TO).

Bruchidius imbricornis (Panzer, 1795) - 1 ex., Italy, Calabria, Cardeto d'Aspromonte, 2729.VI.2017, L. Carrozza and F. Parisi leg., L. Toma det., in traditional fruit orchard (TO).

Bruchidius pygmaeus (Boheman, 1833) - 1 ex., Italy, Calabria, Cardeto d'Aspromonte, 2729.VI., 25-27.VII. and 29-31.VIII. 2017, L. Carrozza and F. Parisi leg., L. Toma det., in traditional fruit orchard (TO). 2 exx., Italy, Calabria, Santo Stefano in Aspromonte 27-29.VI. and 29-31.VIII.2017, L. Carrozza and F. Parisi leg., L. Toma det., in young (YC) and mature coppice (MC).
Bruchidius trifolii (Motschulsky, 1873) - 1 ex., Italy, Calabria, Cardeto d'Aspromonte, 35.X.2017, L. Carrozza and F. Parisi leg., L. Toma det., in traditional fruit orchard (TO).

Bruchus brachialis Fahraeus, 1839 - 1 ex., Italy, Calabria, Cardeto d'Aspromonte, 2729.VI.2017, L. Carrozza and F. Parisi leg., L. Toma det., in traditional fruit orchard (TO).

Bruchus pisorum (Linnaeus, 1758) - 3 exx., Italy, Calabria, Cardeto d'Aspromonte, 2729.VI., 25-27.VII. and 3-5.X.2017, L. Carrozza and F. Parisi leg., L. Toma det., in traditional fruit orchard (TO).

Bruchus rufipes Herbst, 1783 - 1 ex., Italy, Calabria, Cardeto d'Aspromonte, 27-29.VI.2017, L. Carrozza and F. Parisi leg., L. Toma det., in traditional fruit orchard (TO).

Bruchus viciae Olivier, 1795 - 1 ex., Italy, Calabria, Cardeto d'Aspromonte, 25-27.VII.2017, L. Carrozza and F. Parisi leg., L. Toma det., in traditional fruit orchard (TO).

The record of seed beetles during the study on saproxylic coleopterans in the Aspromonte National Park was unexpected firstly because their presence is not actually linked to the chestnut trees characterizing the study area, as well as the method of chosen capture is not selective for these insects. Among the studied specimens we found Paleoachantoscelides gilvus as the predominant species (Fig. II, A). The larva of this species, widely diffused in the regions of central and southern Italy (ZAMPETTI and RICCI, 2012), has Onobrychis aequidentata (Sm.) d'Urv. as host plant, which has practically the same its distribution (GALASSO et al., 2018). The adult of $P$. gilvus, on the other hand, frequents arboreal plants such as Genista scorpius (L.) (Fabaceae), Quercus sp. (Fagaceae), Pinus halepensis Mill. (Pinaceae) and Rosaceae as Prunus spinosa L. (ZAMPETTI and RICCI, 2012). Based on this information, it can be deduced that the massive presence of $P$. gilvus is determined by the wild flora of the study area and not by the cultivated species. The second most abundant species is Bruchidius murinus, widely 


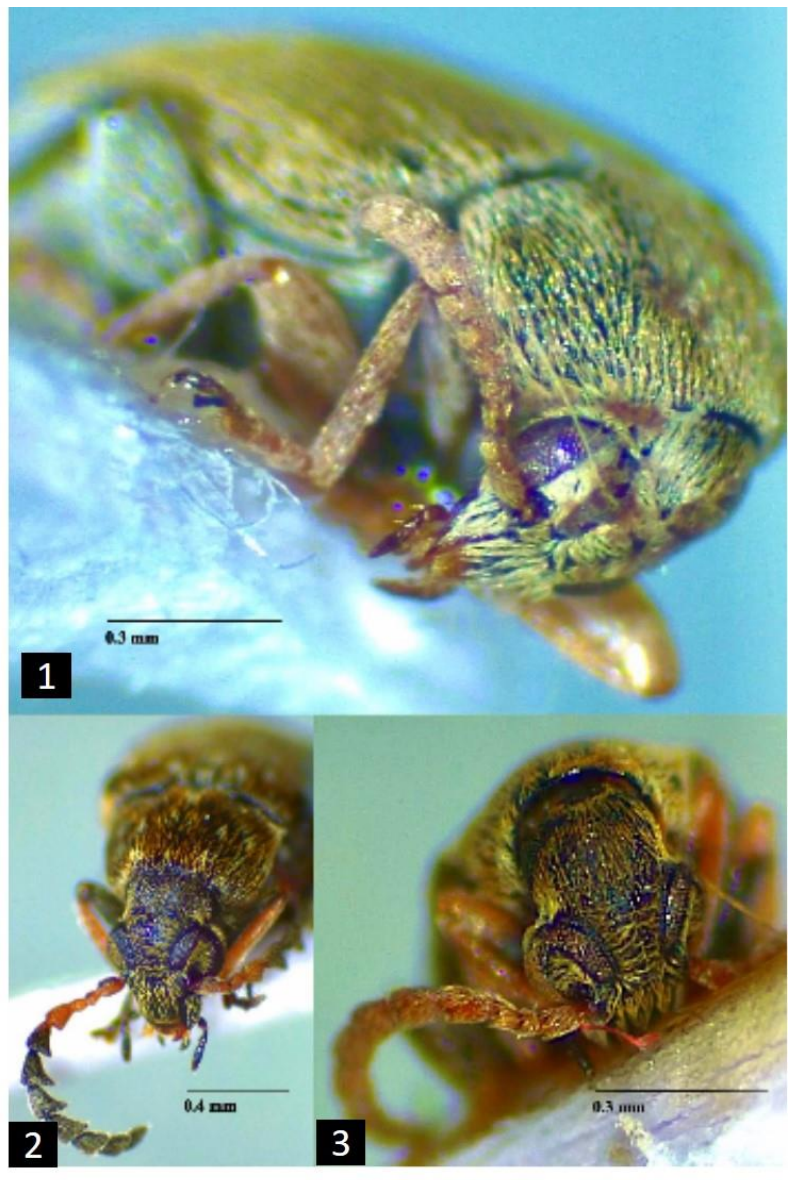

Fig. II. - Frontal and lateral view. 1) Paleoachantoscelides gilvus. Frontal views. 2) Bruchidius murinus, 3) B. tibialis. Photos by L. Toma.

spread throughout Italy (Fig. II, B); this species could be associated with the chestnut (Castanea sativa Mill.) but the data in this regard are still to be confirmed (ZAMPETTI and RICCI, 2012). However $C$. sativa is an abundant essence in the study area as previously described and further observations on this association would be very interesting to deepen. Of particular interest is the discovery of Bruchidius tibialis (Fig. II, C), a species occurring in Liguria and in some regions of central and southern Italy but not reported in Calabria before this study (PARISI $e t$ al., 2018). Among the host plants that the larva of this species frequents are Abutilon holosericeum Scheele (Malvaceae) and Calicotome spinosa (L.) (Fabaceae) while the adults are associated with Ammi majus L. (Apiaceae), Cistus monspeliensis L. (Cistaceae), Calicotome spinosa (L.), Scrophularia sp., Trifolium sp., Vicia faba (L.), V. sativa (L.) and Rosaceae as Crataegus rhipidophylla Ghent. The other species found are common for the Italian fauna, of which they represent almost $20 \%$, and expected for the Calabria region.

Finally, as no studies have been carried out on Bruchinae subfamily, up to now, further researches aimed to deepen the distribution of this group in Aspromonte National Park are desirable on the base of the records here reported.

\section{ACKNOWLEDGEMENTS}

The monitoring was set out in the framework of URCOFI (Unità di coordinamento e potenziamento delle attività di sorveglianza, ricerca, sperimentazione, monitoraggio e formazione in campo fitosanitario) project "Strengthening of the supervision activities and control of pests" in cooperation with regional plant health services. We are grateful to Antonio De Cristofaro, Marco Marchetti, Roberto Tognetti (University of Molise, Italy) and Fabio Lombardi (Mediterranea University of Reggio Calabria, Italy) for technical and scientific support.

\section{REFERENCES}

Bouget C., Brustel H., Brin A., NoBLECOURT T., 2008 - Sampling saproxylic beetles with window flight traps: methodological insights. - Revue d'Écologie, 10: 2132.

Bouchard P., Bousquet Y., Davies A.E., AlONSO-ZARAZAGA M. A., LAWRENCE J.F., LyAL C.H.C., NEWTON A.F., REID C.A.M., SCHMITT M., SLIPINSKI S.A., SMITH A.B.T., 2011 - Family-group names in Coleoptera (Insecta). - ZooKeys, 88: 1-972.

Galasso G., Conti F., Peruzzi L., Ardenghi N.M.G., BANFi E., Celesti-Grapow L., ALBANO A, ALESSANDRINI A., BACCHETTA G., BALLELLI S., BANDINI MAZZANTI M., BARBeris G., Bernardo L., Blasi C., Bouvet D., Bovio M., CECChi L., Del Guacchio E., Domina G., FASCETTi S., Gallo L., GubelLini L., Guiggi A., IAMONico D., Iberite M., JiMÉNEZ-MEJÍAS, E. LATTANZI, D. MARCHETTI, E. MARTINETTO, R.R. MAsin, P. ME- 
DAgli, N.G. PassalacQua, S. PeCCenini, PENNESi R., Pierini B., Podda L., POLdini L., Prosser F., Raimondo F.M., RomaMarzio F., Rosati L., Santangelo A., Scoppola A., SCORTEGagna S., SelvagGi A., Selvi F., Soldano A., StinCA A., WAGENSOMMER R.P., WILHALM T., BARTOLUCCI F., 2018 - An updated checklist of the vascular flora alien to Italy. - Plant Biosystems, 152(3): 556-592.

JOHNSON C.D., KINGSOLVER J.M., 1981 Checklist of the Bruchidae (Coleoptera) of Canada, United States, Mexico, Central America and the West Indies. - Coleopterist Bulletin, 35(4): 409-422.

PARISI F., TOMA L., SIClARI A., 2018 - Reperti. - Bollettino dell'Associazione Romana di Entomologia, 73 (1-4): 85-88.
PARISI F., LOMBARDi F., MARZILIANO P.A., Russo D., De Cristofaro A., Marchetti M., TOGNETTI R., 2020 - Diversity of saproxylic beetle communities in chestnut agroforestry systems. - iForest, 13: 456-465.

SouthGATE B.J., 1979 - Biology of the Bruchidae. - Annual Review of Entomology, 24: 449-473.

Yus-RAmos R., Ventura D., Bensusan K., COELlO-GARCÍA P., GYÖRGY Z., Stojanova A., 2014 - Alien seed beetles (Coleoptera: Chrysomelidae: Bruchinae) in Europe. - Zootaxa, 3826(3): 401-448.

ZAMPETTI M.F., RICCI M.S., 2012 - Guida ai Coleotteri Bruchidi della Fauna Italiana. Sistematica e biologia Gestione e controllo. Darwin Edizioni, Roma, 430 pp. 